\title{
The promoter of filamentation (POF1) protein from Saccharomyces cerevisiae is an ATPase involved in the protein quality control process
}

Iris M Costa ${ }^{1}$, Tallybia HT Nasser ${ }^{1}$, Marilene Demasi ${ }^{2}$, Rafaella MP Nascimento ${ }^{3}$, Luis ES Netto ${ }^{3}$, Sayuri Miyamoto ${ }^{4}$, Fernanda $\mathrm{M} \mathrm{Prado}^{4}$ and Gisele Monteiro ${ }^{1 *}$

\begin{abstract}
Background: The gene YCLO47C, which has been renamed promoter of filamentation gene (POF1), has recently been described as a cell component involved in yeast filamentous growth. The objective of this work is to understand the molecular and biological function of this gene.

Results: Here, we report that the protein encoded by the POF1 gene, Pof1p, is an ATPase that may be part of the Saccharomyces cerevisiae protein quality control pathway. According to the results, Apof1 cells showed increased sensitivity to hydrogen peroxide, tert-butyl hydroperoxide, heat shock and protein unfolding agents, such as dithiothreitol and tunicamycin. Besides, the overexpression of POF1 suppressed the sensitivity of $4 p c t 1$, a strain that lacks a gene that encodes a phosphocholine cytidylyltransferase, to heat shock. In vitro analysis showed, however, that the purified Pof1p enzyme had no cytidylyltransferase activity but does have ATPase activity, with catalytic efficiency comparable to other ATPases involved in endoplasmic reticulum-associated degradation of proteins (ERAD). Supporting these findings, co-immunoprecipitation experiments showed a physical interaction between Pof1p and Ubc7p (an ubiquitin conjugating enzyme) in vivo.
\end{abstract}

Conclusions: Taken together, the results strongly suggest that the biological function of Pof1p is related to the regulation of protein degradation.

Keywords: unfolded protein response, endoplasmic reticulum stress, antioxidant response

\section{Background}

Cells possess several mechanisms to control the quality of their components, such as proteins [1]. One of these mechanisms ensures proper folding and function of proteins, sending misfolded proteins to be degraded by the ubiquitin-proteasome system and represents the best characterized protein quality control process [2-4]. In the lumen of endoplasmic reticulum (ER), one relevant protein quality control mechanism operates, where misfolded proteins are recognized by ER chaperones and some of them are eventually translocated to the cytosol, in the interface with the ER membrane. Finally, the degradation of non-functional proteins can take place by

\footnotetext{
* Correspondence: smgisele@usp.br

'Departamento de Tecnologia Bioquímico-Farmacêutica, Faculdade de Ciências Farmacêuticas, Universidade de São Paulo - USP, São Paulo-SP, Brazil

Full list of author information is available at the end of the article
}

the ubiquitin-proteasome system in a process known as ER-associated degradation (ERAD) [2-4].

The importance of protein quality control mechanisms is evident if it is taken into account that as much as $30 \%$ of all nascent polypeptides are misfolded [5,6]. E3 ubiquitin ligases are associated with ribosomes to degrade proteins with aberrant folds, which mean that several proteins can be degraded during translation [7]. Therefore, it is not surprising that several mutants of genes encoding critical proteasome subunits are lethal. Remarkably, accumulation of misfolded proteins is implicated with several human diseases, especially neurodegenerative illnesses that are associated with protein aggregates [8-10].

Proteins that enter the secretory pathway are directed to the ER, where their folding and post-translational modifications occur. However, when the processing capacity of the ER is overwhelmed, misfolded proteins accumulate in
C Biomed Central

C 2011 Costa et al; licensee BioMed Central Ltd. This is an Open Access article distributed under the terms of the Creative Commons Attribution License (http://creativecommons.org/licenses/by/2.0), which permits unrestricted use, distribution, and reproduction in any medium, provided the original work is properly cited. 
this compartment, which triggers a cell defense mechanism known as the unfolded protein response (UPR). The UPR is mediated by the Ire1p, an RNAse, which is activated when misfolded proteins accumulate in the ER lumen. Activated Ire1p removes an inhibitory intron from the HAC1 mRNA, which, in turn, is efficiently translated. Hac1p is a transcription factor responsible for activating genes related to ERAD. To accommodate the accumulation of misfolded proteins until their degradation or their homeostatic recovery, the transcription factors Opilp and Opi3p (overproducer of inositol 1 and 3 proteins) are responsible for controlling the expression of genes involved in expansion of the ER membrane, especially genes encoding proteins that are involved in lipid synthesis [11-14].

Three well-characterized ERAD pathways are present in yeast: ERAD-L, $-\mathrm{M}$ and $-\mathrm{C}$, depending on the site of the misfolded lesion. Proteins whose misfolded domains are located in the ER lumen are targeted to ERAD-L, whereas proteins with misfolded membrane domains are directed to ERAD-M and proteins with defective domains on the cytoplasmic side of the ER membrane are degraded by the ERAD-C pathway. Therefore, when a protein is misfolded in the ER lumen or membrane, it is transported to the cytoplasm, polyubiquitinated and subsequently degraded by the proteasome (for a review on this process, see [15]).

The ERAD-C pathway is mainly composed by the E3 ubiquitin ligase Doa10p and its associated protein complex. The Doa10p complex is small when compared to the other two ERAD pathway complexes [2]. In addition to Doa10p (the scaffold membrane protein), the Doa10p complex contains Ubc7p (an E2 ubiquitin conjugating enzyme), its anchoring protein Cue1p and the ATPase complex Cdc48, which is composed of the AAA-ATPase Cdc48p, the cofactors Ufd1p and Npl4p and the complex anchorage protein Ubx2p [2].

Some studies describe a post-ER system of protein quality control, which would occur at the Golgi compartment. This system was suggested to be used in addition to the ERAD pathway upon saturation of the ERAD system by misfolded proteins $[16,17]$. Only recently, Wang and Ng (2010) characterized a substrate dependent on post-ER Golgi quality control, the protein Wsclp, which is a transmembrane protein that functions as a sensor of plasma membrane/cell wall integrity [18]. Thus, the description of this quality control process and determination of its specific substrates represented a breakthrough since a novel biological function, i.e. degradation of proteins, was revealed.

Here, we show that Pof1p, a protein that was recently reported as a filamentation promoter protein [19], is an ATPase that is likely involved in the protein degradation pathway. The expression of POF1 gene was able to suppress the sensitivity of $\Delta p c t 1$ strain (mutant for a phosphocholine cytidylyltransferase enzyme) to heat shock; however, the Pof1p enzyme possesses no cytidylyltransferase activity but does have ATPase activity. Some studies have related membrane lipid biosynthesis with the ERAD pathway ([20]; reviewed by [21]) and wide-scale studies of protein-protein physical interactions found Pof1p in complex with Doa10p [22], Ubc7p (Database of Interacting Proteins (DIP), 2010) and Nas2p [23]. Doa10p and Ubc7p are components of the ERAD-C pathway [1], and Nas2p is a protein involved in proteasome assembly [24]. Taken together, the data suggest that the biological function of Pof $1 p$ is related to protein quality control.

\section{Results}

We were interested to identify deletion mutant strains for genes with unknown functions that might be sensitive to oxidative stress. Therefore, several yeast strains were exposed to hydrogen peroxide $\left(\mathrm{H}_{2} \mathrm{O}_{2}\right)$ or tert-butyl hydroperoxide $(t-\mathrm{BOOH})$. Among them, $\triangle$ pof1 (YCL047C ORF was named POF1 due to its involvement in yeast filamentation process [19]) was highly sensitive to these oxidants (Figure 1).

To get insights on the involvement of Pof1 in the antioxidant cell response, a series of bioinformatics analysis were performed (Protein Information Resource (PIR) site, the UniProt Consortium http://pir.georgetown.edu/cgi-bin/ ipcEntry?id=S19376, and the Munich Information Center for Protein Sequences (MIPS) site http://mips.helmholtzmuenchen.de/genre/proj/yeast/searchEntryAction.do?tex$\mathrm{t}=\mathrm{YCL} 047 \mathrm{C}$, indicating that the POF1 gene may belong to the cytidylyltransferase family. Therefore, the primary sequence of POF1 was aligned with the amino acid sequence of the most studied phosphocholine cytidylyltransferase protein in yeast, PCT1, the rate-limiting enzyme in the phosphatidylcholine synthesis pathway, which is a major membrane lipid component. Also, human isoforms of choline (ct human) or ethanolamine (et human) cytidylyltransferases amino acid sequences were aligned with POF1 (Figure 2A). Although the overall similarity among sequences was low (around 10\%), the conserved motif $\mathrm{HxxH}$ [25], which is characteristic of the active site of the cytidylyltransferase family, was present in the predicted primary sequence of POF1.

Accordingly, to investigate the hypothesis that Poflp is a cytidylyltransferase, the biological complementation assay of the PCT1 mutant strain was performed by overexpressing POF1 in cells challenged with heat shock stress because $\Delta p c t 1$ is sensitive to this stress [26]. Overexpression of POF1 was able to reverse the heat shock sensitivity of the $\Delta p c t 1$ strain (Figure $2 \mathrm{~B}$ ), suggesting that Pof1p and Pct1p share a common function. Indeed, as $\Delta p c t 1$ cells, the $\Delta p o f 1$ strain was highly sensitive to heat 


\section{Control YPD}
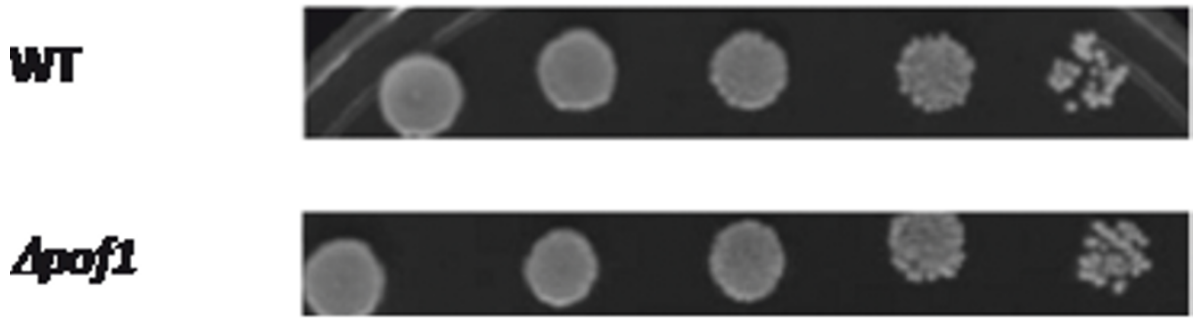

\section{$\mathrm{YPD}+4 \mathrm{mM} \mathrm{H}_{2} \mathrm{O}_{2}$}

WT

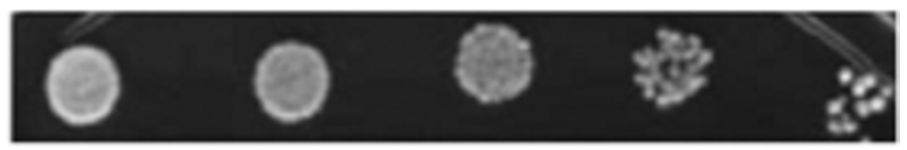

$4 \operatorname{pof} 1$

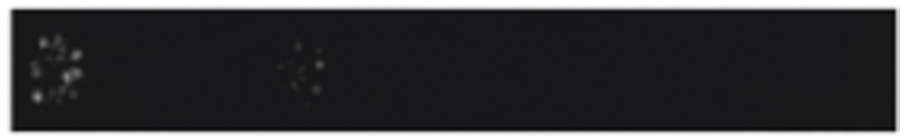

\section{YPD + $1.5 \mathrm{mH} t \mathrm{BOOH}$}

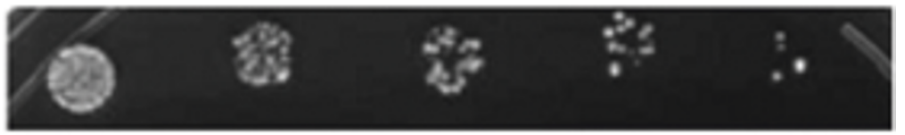

\section{$4 \operatorname{pof} 1$}

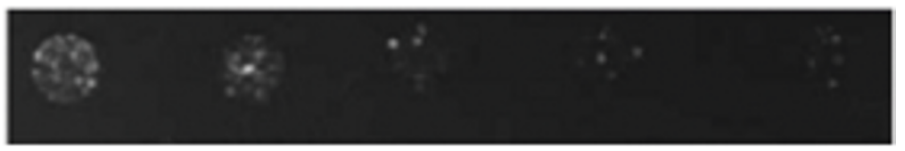

Figure 1 ppof1 cells are sensitive to oxidative stress. A representative viability assay showing cells exposed to hydrogen peroxide $\left(\mathrm{H}_{2} \mathrm{O}_{2}\right)$ or tert-butyl hydroperoxide $(t-\mathrm{BOOH})$ on rich solid media (YPD). The cells (collected at stationary phase) were diluted to $\mathrm{OD}_{600} \mathrm{~nm}=0.2$, followed by 4 serial dilutions of $5 \mathrm{X}$. A total of $5 \mu \mathrm{L}$ of each dilution were spotted on the plates, which were incubated at $30^{\circ} \mathrm{C}$ for $48 \mathrm{~h}$ and photographed.

shock. Moreover, overexpression of POF1 also partially rescued the wild type phenotype in $\triangle p o f 1$ strain.

Pure, recombinant Pof1p was obtained in the soluble fraction (Figure 3A), and Pof1p was assayed for phosphocholine or phosphoethanolamine cytidylyltransferase activities. Intriguingly, POF1 did not hydrolyse CTP as analyzed by thin layer chromatography (TLC), but instead it displayed ATPase activity (Figure 3B). The ATPase activity was independent of the presence of phospholipid precursors in the reaction media, indicating that Pof1p was not interacting with these substrates, at least when hydrolyzing ATP. The reaction products were also analyzed by mass spectrometry, but no CDP-choline or CDP-ethanolamine could be detected (data not shown).

Since the ability of Pof $1 p$ to complement Pct1p function during heat shock is not related to CDP-choline activity, the hypothesis that Pof1p participates in some protein quality control was tested. Cells were submitted to ER stress, by exposing them to high concentrations of dithiothreitol (DTT) and tunicamycin (a protein glycosylation inhibitor). Both agents are well known to provoke accumulation of unfolded proteins in the ER. $\Delta$ pof 1 cells displayed higher sensitivity to ER stress agents than wildtype cells and $\Delta u b c 7$ cells (mutant strain which lacks $U B C 7$ gene which encodes ubiquitin conjugating enzyme 


\begin{abstract}
A

\begin{tabular}{cccc}
\hline \\
49
\end{tabular}
\end{abstract}

B

YPD control $30^{\circ} \mathrm{C}$

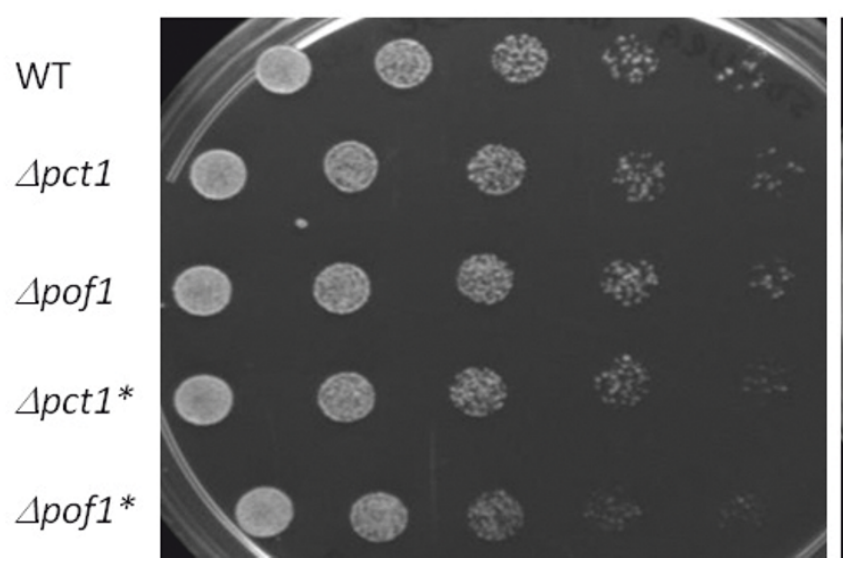

YPD $37^{\circ} \mathrm{C}$

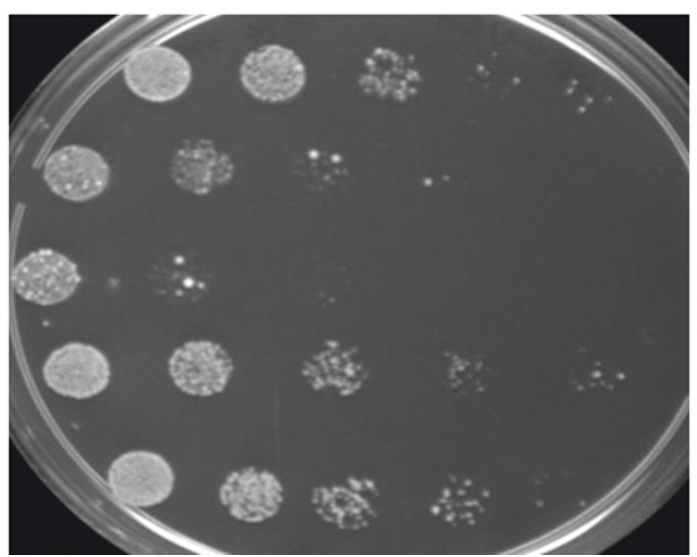

Figure 2 POF1 and PCT1 sequences and functional analyses. (A) Clustal W (Megalign software) primary sequence alignment of the cytidylyltransferase family. The conserved motif $\mathrm{HxxH}$ is enclosed in the box. Ct human = choline cytidylyltransferase from humans (gi 166214967); et human = ethanolamine cytidylyltransferase from humans (gi 1817548); pct1 yeast = phosphocholine cytidylyltransferase from S. cerevisiae (gi 1323361); ycl047c = Pof1p (gi 6319802). (B) Complementation assays. The cells were exposed to heat shock (37 ${ }^{\circ} \mathrm{C}$ ) or control conditions $\left(30^{\circ} \mathrm{C}\right)$ for $17 \mathrm{~h}$, serially diluted and spotted on YPD plates, which were incubated for $48 \mathrm{~h}$ at $30^{\circ} \mathrm{C}$ and photographed. The asterisk denotes cells transformed with the plasmid pYES-TOPO+POF1 for overexpression of Pof1.

involved in ERAD, a control cell line [27]) (Figure 4), suggesting that Pof1p is involved in UPR. Besides, Pof1p presented an ATPase-specific activity of $5 \mathrm{nmol}$ of released phosphate per hour per $\mu \mathrm{M}$ enzyme (Figure $5 \mathrm{~A}$ ). This activity is comparable to the ATPase activity of the ERAD-associated protein Kar2p (approximately $4 \mathrm{nmol}$ of phosphate release per hour per $\mu \mathrm{M}$ of Kar2p in complex with both the nucleotide exchanger Lhs1p and the DnaJ-like partner) [28], indicating that this enzymatic process is relevant in vivo.

Interestingly, using the bioinformatics tool PIPE 2 (Protein-Protein Interaction Prediction Engine, freely available at http://pipe.cgmlab.org/), with the default cutoff of 0.06 (sensitivity $=57 \%$ and specificity $=89 \%$ ), we could predict an interaction between the Kar2p ATPase and Pof1p [29]. At a lower cutoff of 0.04 (sensitivity $=70 \%$ and specificity $=83 \%$ ), an interaction between Pof $1 \mathrm{p}$ and Cdc48p was predicted, which is the ATPase present in all types of ERAD pathways [2,29]. As a positive control, Pof1p and Kss1p interaction was predicted using the default cutoff of 0.06 . This is in agreement with experimental data showing through transcriptome data that this mitogen-activated protein kinase (MAPK) (involved in signal transduction pathways that control filamentous growth and pheromone response) interacted with POF1 [19]. As a negative control, the ATPase from vacuole VMA10 was not predicted to be an interacting partner with Pof1p, even using a lower cutoff of 0.01 (sensitivity $=92 \%$ and specificity $=$ $47 \%)$.

To validate these in silico protein-protein interactions predictions, anti-Pof1p rabbit polyclonal antibodies were produced. The interactions between Pof1p with Doa10p and with Ubc7p, two components of the ERAD pathway, were investigated, since these complexes were previously described [22]. The physical interaction between Nas2p and Pof $1 p$ could not be investigated because there is no commercially available Nas2p antibody. Doa10p and Pof1p did not co-immunoprecipitate under the cell growth conditions tested (data not shown); however, we did observe a physical interaction between Ubc7p and Pof1p in vivo (Figure 5B). The migration of the band relative to the Ubc7p and Pof1p corresponded to the sum of the molecular mass of the two proteins. Since Western blot was performed in denaturing conditions (after SDS-PAGE) the 


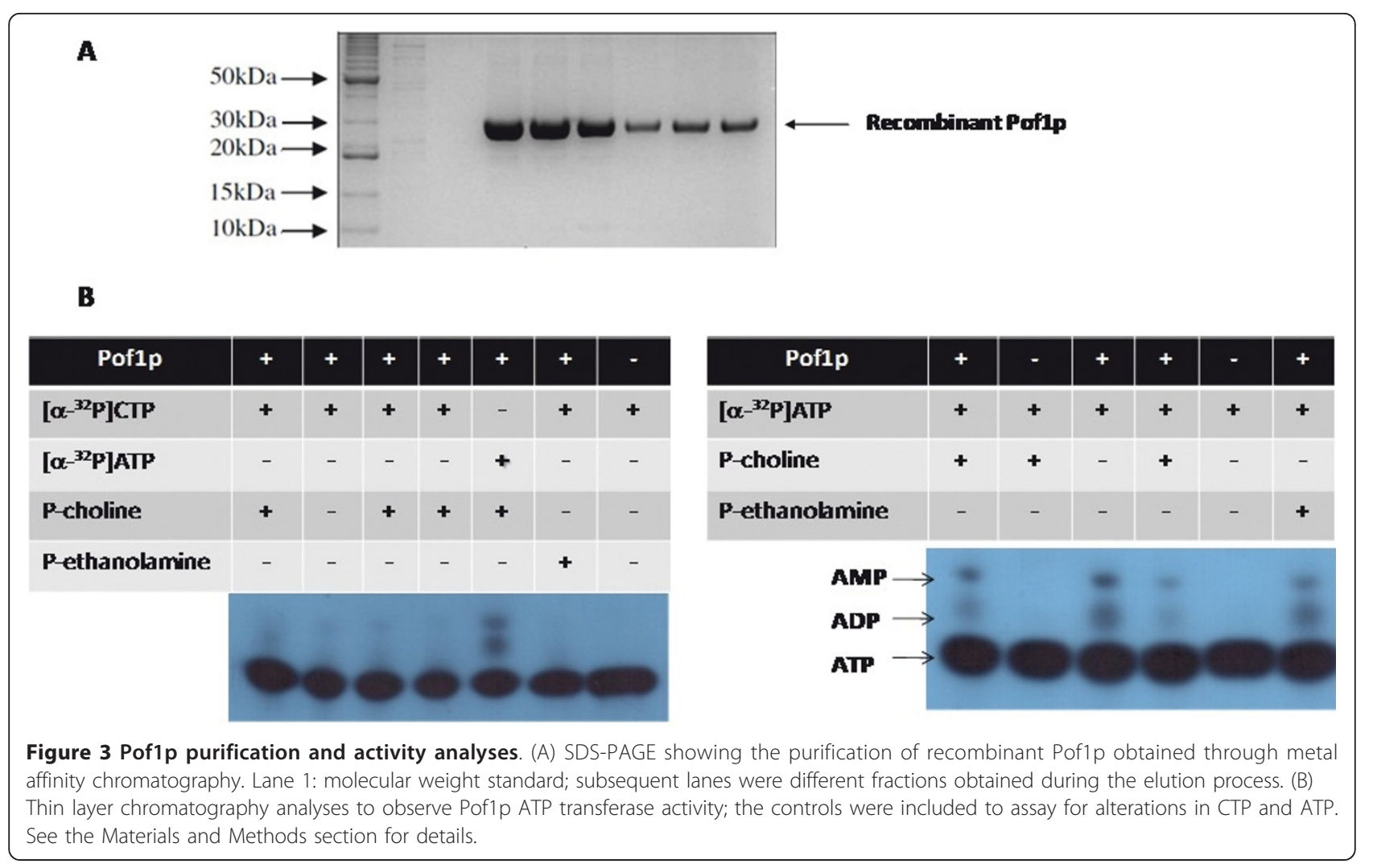

band depicted with asterisk might be observed due to the formation of a mixed disulfide bond between Pof1p and Ubc7p. Pof1p possesses six cysteine residues. Probably the concentrations of DTT ( $1 \mathrm{mM})$ employed were too low to reduce the mixed disulfide between Poflp and Ubc7p.

Taking advantage of the anti-Pof1p antibody, the Pof1p sub-cellular distribution was studied. A punctuated Pof1p distribution in was observed in wild-type cells (Figure 6), which was more evident in $\Delta p c t 1$ cells. This is in agreement with higher protein expression of Pof1p in $\Delta p c t 1$ cells, which was also observed by Western blotting (data not shown), suggesting a compensatory response. Based on previous immunocytochemistry studies [30], we speculate that Pof1p localizes to the Golgi compartment.

\section{Discussion}

The first suggestion that the POF1 gene was related to the protein quality control response arose from widescale studies about the relationship between the ERAD and UPR systems [20]. Indeed, mRNA levels of POF1 gene were significantly increased in cells that were treated with ER stress agents (DTT and tunicamycin), and this induction was dependent on both Ire1p and Hac1p. In addition, a proteasome inhibitor (PS-341) provoked a four-fold induction of POF1 gene expression [31].
Furthermore, the expression of $P O F 1$ gene is repressed in the Aopi1 strain [20], suggesting an involvement of Pof1p with membrane and protein metabolism. The viability data presented here are in agreement with this idea, especially when considering the fact that all stressful conditions tested (oxidative, heat shock, and ER stress in Figures 1, 2 and 4) are well known to provoke protein misfolding. Yet, oxidative stress and heat shock (Figures 1 and 2) caused the most severe phenotypes in $\Delta p o f 1$ cells, which is likely due to the fact that these stresses damage both membrane and protein homeostasis [32,33]. The fact that POF1 overexpression was able to complement the function of PCT1 in $\triangle p c t 1$ cells during heat shock (Figure 2 ) and its expression levels by Opi1p [20] suggests the involvement of Pof1p in membrane lipid metabolism. In addition, the levels of Pof1p are augmented in $\Delta p c t 1$ cells (Figure 6 and western blot analyses - data not shown), which indicated that Pof1p might at least partially backing up Pct1p.

However, the molecular function of Pof1p could not be directly related to membrane lipid synthesis although the protein displayed ATPase activity (Figure 3). Pof1p ATPase activity was efficient enough to occur in vivo, and its specific activity was comparable to Kar2p, an Hsp70 chaperone from the ER that reaches its maximum activity (approximately $4 \mathrm{nmol}$ of released phosphate per 


\section{ControlSD}

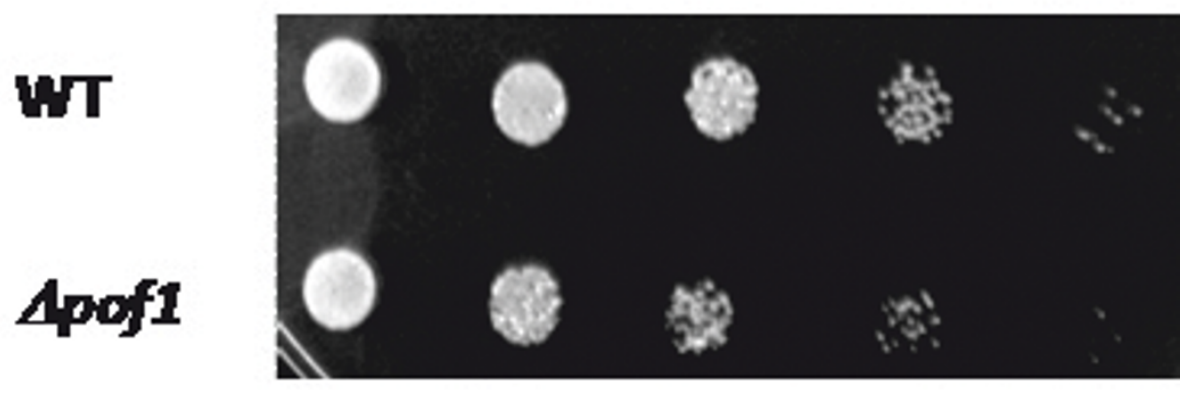

\section{$\mathrm{SD}+2 \mu \mathrm{g} / \mu \mathrm{L}$ tunicamycin}
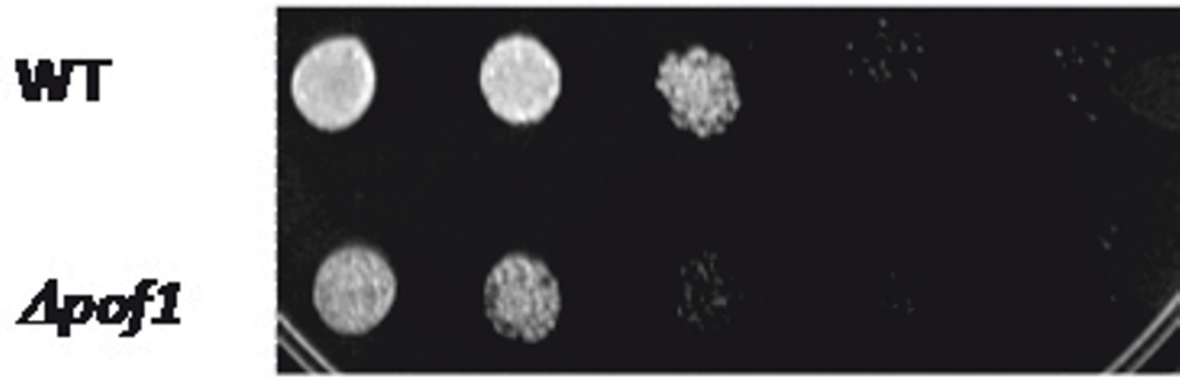

\section{$\mathrm{SD}+4 \mathrm{mM} \mathrm{DTT}$}
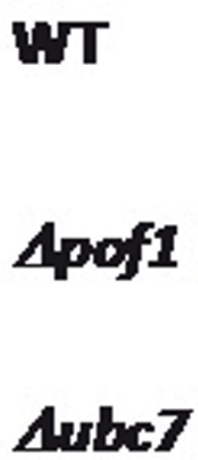

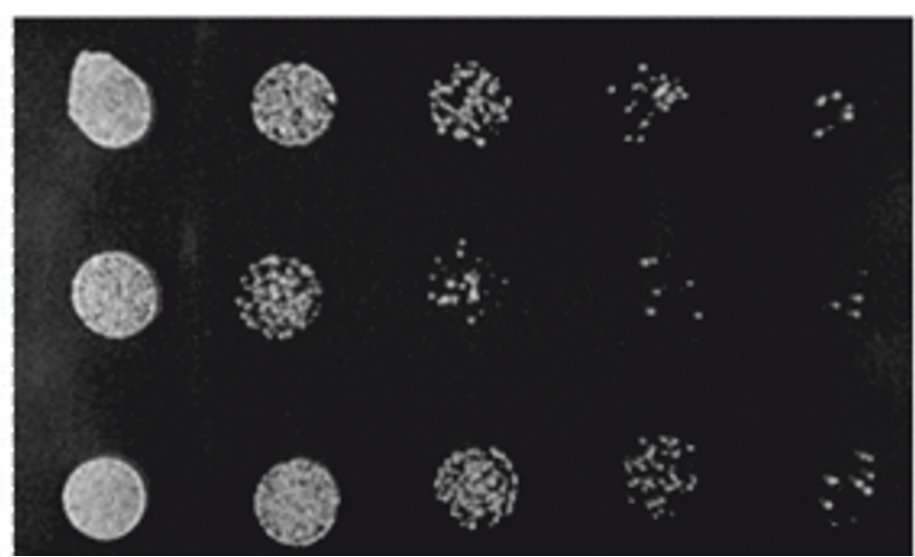

Figure $4 \Delta$ pof 1 cells are sensitive to protein unfolding. The cells from the stationary phase of growth were diluted to $\mathrm{OD}_{600 \mathrm{~nm}}=0.2$, followed by 4 serial dilutions of $5 \mathrm{X}$. A total of $5 \mu \mathrm{L}$ of each dilution were spotted on SD complete media plates containing no unfolding agent, DTT or tunicamycin. The plates were incubated at $30^{\circ} \mathrm{C}$ for $48 \mathrm{~h}$ and photographed.

hour per $\mu \mathrm{M}$ of Kar2p) when in complex with co-chaperones Sec63p (a soluble protein that contains a J-domain) and Lhs1p [28]. Pof1p ATPase activity was also comparable with p97, the mammal homolog of yeast Cdc48p, which is the main ERAD ATPase [34,35]. As indicated by PIPE 2 bioinformatics analyses Pof1 $\mathrm{p}$ is predicted to interact with others proteins involved in ERAD, such as Kar2p and Cdc48p.

In addition to viability and activity results indicating that Pof $1 p$ is involved in protein quality control, protein-protein interactions studies in wide-genome scale indicated the participation of Pof1p as a component of 


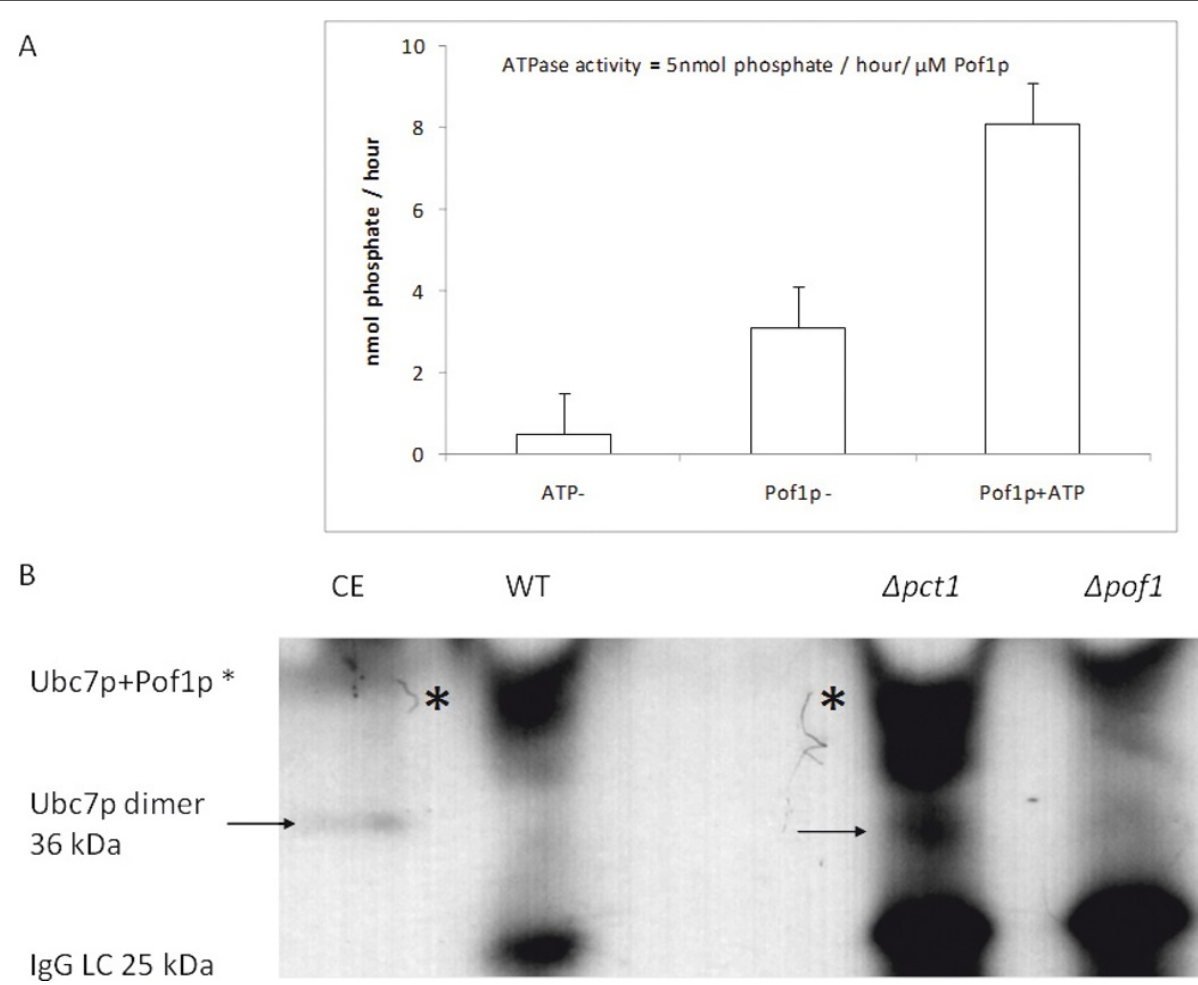

Figure 5 ATPase activity of Pof1p and its physical interaction with Ubc7 (ubiquitin conjugase 7) protein. (A) Hydrolysis of ATP as measured by the PiPerTM Phosphate Assay Kit (Invitrogen). (-) ATP represents the result of the reaction in the absence of ATP; (-) POF1 represents the result of the spontaneous ATP hydrolysis in the absence of Pof1p; the lane labeled "Pof1p + ATP" contains the complete reaction. The assays were performed at $37^{\circ} \mathrm{C}$ for $1 \mathrm{~h}$. (B) Western blot analyses of Ubc7p using the commercial antibody Ube2G2 (Abcam). The fractions were obtained from co-immunoprecipitation assays using Pof1 p polyclonal antibody from the following protein extract: WT = wild type; $\Delta p c t 1$ and $4 p o f 1$. The asterisk shows the Pof1p-Ubc7p complex. CE = total soluble wild type cell extract; IgG LC = IgG light chain. The arrow points Ubc7p dimer.

the ubiquitin-proteasome pathway. Hesselberth et al. (2006) described the Doa10p-Pof1p complex using protein microarray technology, whereas The DIP site and Genemania Fast Gene Function Predictions tool (September $2^{\text {nd }}, 2010$ database update) reported the Ubc7pPof1p interaction. Under our growth conditions of stationary growth phase and galactose-containing medium, we did not observe Doa10p-Pof1p co-immunoprecipitation (data not shown); however, under the same growth conditions, we detected an Ubc7p-Pof1p interaction (Figure 5B).

Still taking advantage of a polyclonal Pof1p antibody produced in this study, a punctuated Pof1p cell distribution was observed (Figure 6) that is very similar to proteins localized in the Golgi compartment [30]. Although these results are preliminary, the immunocytochemical data clearly showed that Pof1p is not uniformly distributed in the cytoplasm and does not co-localize with the nucleus or mitochondria where DNA is stained with DAPI (see merged figure, Figure 6). Since ER protein distribution is expected to be perinuclear, Pof1b probably was not located in this organelle.
The post-ER Golgi protein quality control pathway has already been reported, and at least one specific substrate of this system has been characterized [36]. Taken together, the results suggest that Pof1p is an ATPase that interacts with the ubiquitin conjugating protein (an E2) Ubc7p and protects cells from accumulating misfolded proteins caused by oxidative, heat, reductive or chemically (tunicamycin) stressful conditions. A possible explanation for the functional relationship between Pct1p and Pof $1 p$ could be due to the participation of Pof $1 p$ in protein quality control. For instance, the autophagy system controls the turnover of the majority of stable proteins and coordinates degradation through the engulfment of these polypeptides into a double-lipid bilayer - the autophagosome - which fuses with a lysosome/vacuole in which degradation occurs [37]. Given that $\Delta p c t 1$ cells have deficient membrane lipid turnover [38], which probably results in lower membrane repositioning during autophagy, the ER expansion would be impaired. In this situation, an increase in Pof1p levels, together with several other proteins, would improve the proteasomal degradation process. 


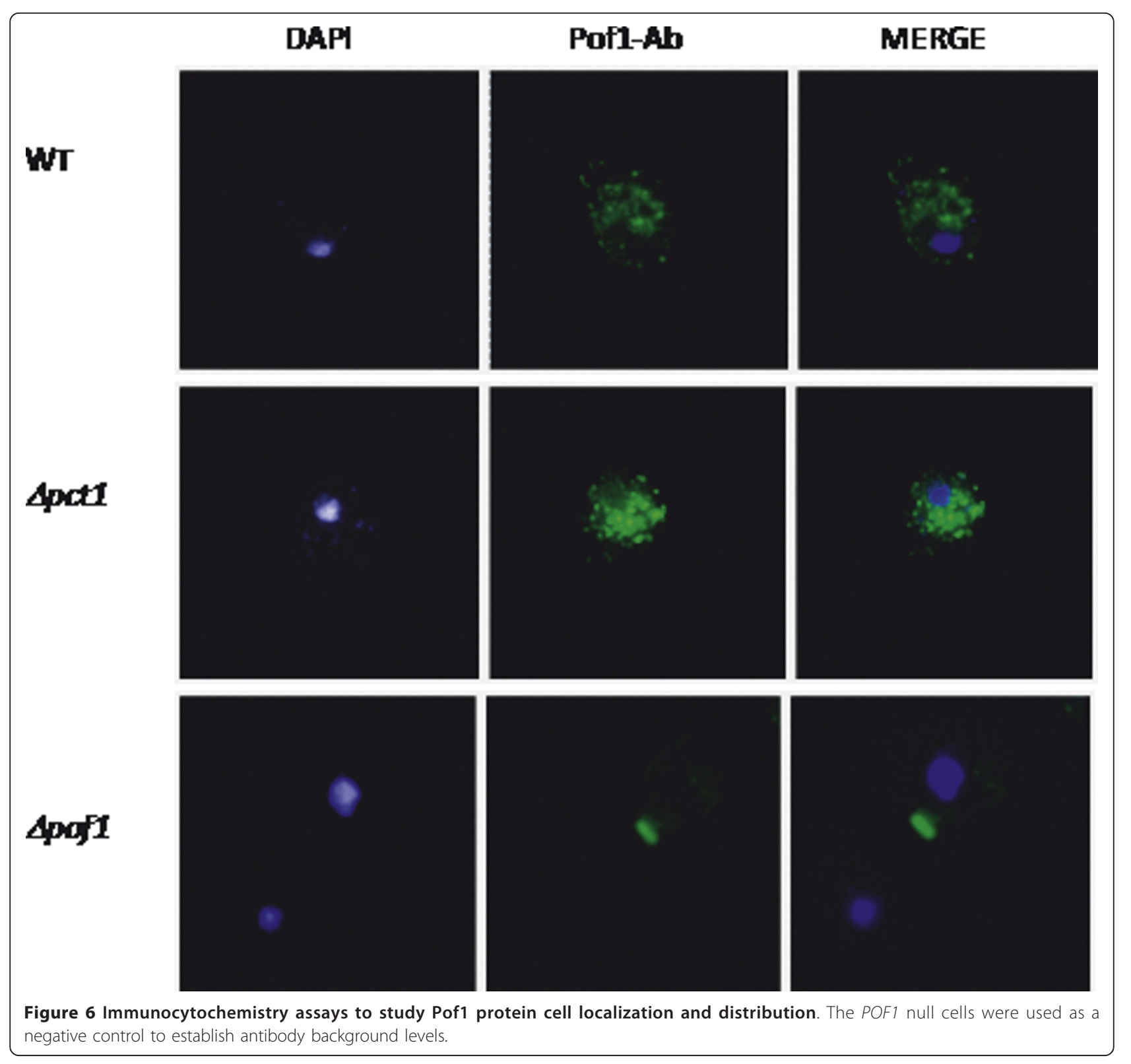

The results presented here, together with previously published data, allow us to speculate that Pof1p is part of the ERAD pathway as an E3 ubiquitin ligase. Pof1p may be involved in substrate recognition during ubiquitin marking because it interacts physically with an E2 ubiquitin conjugating enzyme, Ubc7p, and it is important in the unfolded protein response. $\Delta p o f 1$ cells were more sensitive to reductive stress than the $\Delta u b c 7$ cells (cells in which Ubc7p is absent), this last a well-characterized protein that participates in the ERAD-C pathway. A possible substrate would be the MAP kinase molecule Kss1p, which interacts physically with Pof1p [19]. As mentioned above, Kss1p is a kinase involved in the control of filamentous growth and the pheromone response.
Fasolo et al. (2011) observed that $\Delta p o f 1$ cells are defective in invasive growth and pseudohyphal growth. We hypothesize that the phenotype observed in $\Delta p o f 1$ cells is due to the absence of stability regulation of Kss1p exerted by Poflp.

Therefore, the results described here showed that a protein involved in the yeast-to-hyphal transition [19] possesses ATPase activity and is important in the response of yeast to various stresses. A study on gene expression modulation during yeast filamentous-form growth showed an enriched number of genes involved in protein quality control, such as N-linked glycosylation, ubiquitin-dependent protein catabolism and ER to Golgi transport. Moreover, this study pinpointed the 
$26 \mathrm{~S}$ proteasome as an important component in the regulation of S. cerevisiae filamentous growth [39]. The yeast-to-hyphal transition is a response of several fungi to stressful conditions. For the majority of pathogenic fungi, this transformation is an essential step in their infectious process, and modifications in plasma membrane and cell wall constituents have been implicated $[40,41]$. The mechanisms that trigger the transition to filamentous growth in $S$. cerevisiae are associated with carbon or nitrogen stresses $[39,42]$. The interplay between the filamentation process and protein quality control may be an important feature that deserves to be further investigated.

\section{Conclusions}

This study characterized the molecular function of Pof1p as an ATPase involved in protein quality control. Pof1p was important to yeast defense against oxidative, heat shock and chemically induced stress. Several protein quality control components are still poorly described, despite their importance in neurological diseases. The molecular characterization of the components in yeast can be useful to understand the function of conserved human proteins.

\section{Methods}

Chemicals: $\mathrm{t}-\mathrm{BOOH}$, tunicamycin and DTT were purchased from Sigma Chemical Company (St. Louis, MO, USA). The other chemicals used were analytical grade or better. $\mathrm{H}_{2} \mathrm{O}_{2}$ (30\%) was obtained from Merck.

Yeast strains and growth conditions: The yeast strains used here were obtained from the Yeast Deletion Clones repository (Invitrogen - Carlsbad, CA, USA). The wild-

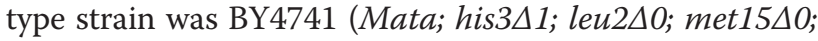
ura3 $\Delta 0$ ); the mutant strains were $\Delta$ pof1 (Mata; his $3 \Delta 1$;

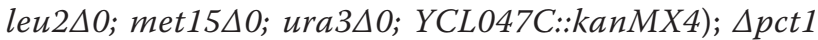

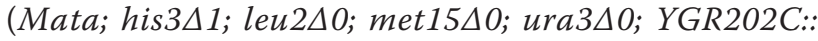

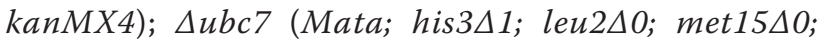
ura3 $\triangle 0$; YMR022W::kanMX4). The yeast cells were grown in YPD (1\% yeast extract, $2 \%$ peptone and $2 \%$ dextrose), YPGAL (1\% yeast extract, $2 \%$ peptone and $2 \%$ galactose) or complete synthetic medium $(0.17 \%$ yeast nitrogen base (YNB), 0.5\% ammonium sulfate, all required amino acids plus $2 \%$ glucose). SD = synthetic dextrose medium. For most analyses, when yeast strains were grown on glucose or galactose, the cells were harvested by centrifugation at stationary phase, which corresponds to an $\mathrm{OD}_{600 \mathrm{~nm}}$ between 2.0 and 5.0.

Viability assays: The tolerance of yeast cells to $\mathrm{H}_{2} \mathrm{O}_{2}$ or to $t$-BOOH was determined by the spot test, as described below. Inoculates were obtained from cells that were grown overnight in YPD or complete synthetic media with $2 \%$ glucose (indicated in the figures). Inoculates were diluted to $\mathrm{OD}_{600 \mathrm{~nm}}=0.2$, and yeasts were grown until cell density reached stationary phase (around $16 \mathrm{~h}$ ). Finally, the cell cultures were diluted again to $\mathrm{OD}_{600 \mathrm{~nm}}=0.2$, and then four subsequent 1:5 dilutions of these cell suspensions were performed. A $5 \mu \mathrm{L}$ droplet of each dilution was plated onto YPD or complete synthetic medium (SD) plus agar with the stress agent. Peroxides were added to plates at the concentrations indicated in the figures. DTT or tunicamycin was spread onto the plates just before use. To test cell viability under heat shock conditions, the strains were grown until cell density reached $\mathrm{OD}_{600 \mathrm{~nm}}=0.8$, and they were divided into two aliquots, which were incubated at $30^{\circ} \mathrm{C}$ (control) or $37^{\circ} \mathrm{C}$. The serial dilutions (starting from $\mathrm{OD}_{600 \mathrm{~nm}}=0.2$ ) were spotted onto YPD agar plates, and the plates were incubated for $48 \mathrm{~h}$ at $30^{\circ} \mathrm{C}$.

Construction of yeast overexpression vector pYESTOPO + POF1: The coding region of POF1 gene was cloned from yeast genomic DNA using the following specific primers: POF1 forward 5'TGCTGTCACATATGAAGAAGAC and POF1 reverse 5'TAAACGGATCCTCAA TCAAATATTG, which contain NdeI or BamHI restriction enzyme sites adaptors, respectively (underlined sequences). This PCR-isolated DNA fragment was purified with the GFX PCR DNA and Gel Band Purification kit (GE Healthcare, Uppsala, Sweden) and ligated into the pYES-TOPO backbone to form pYES-TOPO + POF1 for yeast expression (controlled by GAL1 promoter) and into the $\mathrm{pET} 15 \mathrm{~b}$ vector to generate $\mathrm{pET} 15 \mathrm{~b}+$ POF1 for bacterial expression (controlled by $\mathrm{T} 7$ promoter). The POF1 gene was added to pYES2.1-TOPO TA (Invitrogen) reaction media according to the manufacturer. The ligation product was transformed into Escherichia coli DH5 $\alpha$ bacteria strain by electroporation. The transformed clones were grown in $\mathrm{LB}+$ ampicillin $(100 \mu \mathrm{g} / \mathrm{mL})$, and the plasmids were isolated with the Illustra plasmidPrep Mini Spin Kit (GE Healthcare). The clones were analyzed for proper directionality of the insertion by PCR using the TOPO GAL forward primer and the POF1 reverse primer. The correct plasmids were sequenced and transformed into the respective yeast strains by electroporation [43].

Heterologous expression and purification of recombinant Pof1p: Recombinant Pof1p, which possesses an Nterminal His-tag, was expressed in the E. coli BL21 (DE3) strain that was transformed with the pET15b-Pof1p plasmid (the POF1 coding region was cloned into the expression vector $\mathrm{pET} 15 \mathrm{~b}$ from Novagen using the $\mathrm{NdeI}$ and BamHI restriction sites). The cells were cultured $(50 \mathrm{~mL})$ overnight in LB + ampicillin $(100 \mu \mathrm{g} / \mathrm{mL})$, transferred to 1 $\mathrm{L}$ of fresh $\mathrm{LB}+$ ampicillin medium and cultured further until the $\mathrm{OD}_{600 \mathrm{~nm}}$ reached 0.6-0.8. IPTG was added to a final concentration of $1 \mathrm{mM}$. After $3 \mathrm{~h}$ of incubation at $37^{\circ} \mathrm{C}$, the cells were harvested by centrifugation. The pellet was washed and suspended in the start buffer composed of $50 \mathrm{mM}$ Tris- $\mathrm{HCl}$ (pH 7.4), $100 \mathrm{mM} \mathrm{NaCl}$ and $20 \mathrm{mM}$ 
imidazole. The cells were sonicated twice for $45 \mathrm{~s}(40 \%$ amplitude), followed by $30 \mathrm{~s}$ on ice between sonications using a Branson Cell Disruptor. The cell extracts were kept on ice during streptomycin sulfate treatment ( $1 \%$ for $20 \mathrm{~min}$ ), and the suspension was centrifuged at $16,000 \mathrm{~g}$ for $30 \mathrm{~min}$ to remove nucleic acid precipitates and cell debris. Finally, the extracts were applied to a Hi-trap nickel-affinity column (Life Technologies). The conditions for protein purification were optimized using the gradient procedure for imidazole concentration described by the manufacturer.

Thin Layer Chromatography (TLC) analyses: The assays were performed as previously described [44]. Briefly, the reaction media contained $50 \mathrm{mM}$ Tris- $\mathrm{HCl}(\mathrm{pH} 7.4)$, $100 \mathrm{mM} \mathrm{NaCl}, 10 \mathrm{mM} \mathrm{MgCl}_{2}, 20 \mu \mathrm{M}$ phosphatidylcholine:oleate vesicles, $10 \mathrm{mM}$ DTT, $1.5 \mathrm{mM}$ phosphocholine (or $2 \mathrm{mM}$ phosphoethanolamine), $1 \mu \mathrm{g} / \mu \mathrm{L}(20 \mu \mathrm{M})$ Pof1p and $200 \mu \mathrm{Ci} / \mu \mathrm{mol}$ of $\left[\alpha-{ }^{32} \mathrm{P}\right] \mathrm{CTP}$ or $\left[\alpha-{ }^{32} \mathrm{P}\right] \mathrm{ATP}$. The reactions were incubated at $37^{\circ} \mathrm{C}$ overnight in the presence of $\left[\alpha-{ }^{32} \mathrm{P}\right] \mathrm{CTP}$ or $2 \mathrm{~h}$ in the presence of $\left[\alpha-{ }^{32} \mathrm{P}\right] \mathrm{ATP}$. Controls were subjected to the same conditions in the absence of Pof1p. The reactions were analyzed by TLC at room temperature using silica gel plates (Merck) with a solvent system composed of ethanol/ $/ \mathrm{NH}_{4} \mathrm{OH}(1: 1)$. The plates were autoradiographed, and the resulting bands were compared with $\left[\alpha-{ }^{32} \mathrm{P}\right] \mathrm{CTP}$ or $\left[\alpha-{ }^{32} \mathrm{P}\right] \mathrm{ATP}$ without any incubation or addition of enzyme.

ATPase activity. The reactions containing $1 \mathrm{mM}$ ATP, $1 \mu \mathrm{M}$ Pof1p, $5 \mathrm{mM} \mathrm{MgCl}$ and $100 \mathrm{mM}$ Tris- $\mathrm{HCl}(\mathrm{pH}$ 7.5) were incubated at $37^{\circ} \mathrm{C}$ for $1 \mathrm{~h}$. Subsequently, the reactions were boiled for $5 \mathrm{~min}$ and centrifuged for $10 \mathrm{~min}$ at $16,000 \mathrm{~g}$. The $\mathrm{P}_{\mathrm{i}}$ Per Phosphate assay mix was added to the supernatant according to the manufacturer's instructions (Molecular Probes - Invitrogen). The reactions were incubated at $37^{\circ} \mathrm{C}$ for an additional $1 \mathrm{~h}$ in the dark. The absorbance of resorufin, the Amplex Red reagent reaction product, was detected by its absorbance at $565 \mathrm{~nm}$. A calibration curve with known concentrations of inorganic phosphate was used to quantify the $P_{i}$ released during the ATPase reactions. Controls without Pof1p and without substrate (ATP) were subjected to the same conditions.

Co-immunoprecipitation assays: Wild type, $\Delta p c t 1$ and $\Delta p o f 1$ cells were grown until stationary phase in synthetic galactose complete medium. The cells were centrifuged and washed with $1 \mathrm{X}$ phosphate-buffered saline (PBS). The cells were lysed using glass beads in lysis buffer (50 mM Hepes (pH 7.5), 5 mM EDTA, $150 \mathrm{mM}$ $\mathrm{NaCl}, 300 \mathrm{mM} \mathrm{KCl}, 1 \%$ Triton X-100, $2 \mathrm{mM}$ PMSF, 5\% glycerol and $20 \mathrm{mM} \beta$-mercaptoethanol). The insoluble fraction was separated by centrifugation at $16,000 \mathrm{~g}$ for $30 \mathrm{~min}$ and $4^{\circ} \mathrm{C}$. The soluble fraction was incubated with a Dynabead-anti-Pof1p complex overnight at room temperature under gentle agitation. The complexed proteins were washed three times using the washing buffer provided by the Dynabeads Protein G kit (Invitrogen), and the samples were eluted using $20 \mu \mathrm{L}$ of elution buffer (provided in the kit), incubated for $10 \mathrm{~min}$ at $70^{\circ}$ $\mathrm{C}$ in $10 \mu \mathrm{L}$ of $5 \mathrm{X}$ protein SDS-PAGE loading buffer and $1 \mathrm{mM}$ DTT (recommended $10 \mathrm{mM}$ ). One-third of each sample was subjected to western blot analyses.

Western blot analyses: Immunoblot analyses were performed using rabbit polyclonal antibodies against Pof1p produced in this study by immunization with pure recombinant Pof1p. The commercial antibodies from Abcam were used to study Doa10p (mouse monoclonal antibody to MARCH6 (ab56594)) and Ubc7p (rabbit polyclonal antibody to Ube2G2 (ab97279)). Proteins were transferred to nitrocellulose, and the processing of nitrocellulose blots was performed using the BioRad system. The HRP and luminol-based reagent from ECL (Amersham GE Healthcare) was used as a detection system. The membranes were autoradiographed using Amersham Hyperfilm and photo-documented.

\section{Acknowledgements}

We would like to thank Fundação de Amparo à Pesquisa do Estado de São Paulo (FAPESP), Conselho Nacional de Desenvolvimento Científico e Tecnológico (CNPq) and Coordenação de Aperfeiçoamento de Pessoal de Nível Superior (CAPES) for financial support.

\section{Author details}

${ }^{1}$ Departamento de Tecnologia Bioquímico-Farmacêutica, Faculdade de Ciências Farmacêuticas, Universidade de São Paulo - USP, São Paulo-SP, Brazil. 'Laboratório de Bioquímica e Biofísica, Instituto Butantan, São PauloSP, Brazil. ${ }^{3}$ Departamento de Genética e Biologia Evolutiva, Instituto de Biociências, Universidade de São Paulo - USP, São Paulo-SP, Brazil. ${ }^{4}$ Departamento de Bioquímica, Instituto de Química, Universidade de São Paulo - USP, São Paulo-SP, Brazil.

\section{Authors' contributions}

IMC, THTN performed the majority of the experiments. SM and FMP carried out TLC and mass spectrometry analyses. MD and RMPN executed the antibody production and immunocytochemistry studies. GM and LESN have made substantial contributions to conception and design, analysis and interpretation of data. All authors have been involved in drafting the manuscript or revising it critically for important intellectual content.

\section{Competing interests}

The authors declare that they have no competing interests.

Received: 31 August 2011 Accepted: 28 December 2011

Published: 28 December 2011

\section{References}

1. Leidhold C, Voos W: Chaperones and proteases-guardians of protein integrity in eukaryotic organelles. Ann N Y Acad Sci 2007, , 1113: 72-86.

2. Carvalho P, Goder V, Rapoport TA: Distinct ubiquitin-ligase complexes define convergent pathways for the degradation of ER proteins. Cell 2006, 126:361-373.

3. Denic V, Quan EM, Weissman JS: A luminal surveillance complex that selects misfolded glycoproteins for ER-associated degradation. Cell 2006, 126:349-359.

4. Carvalho P, Stanley AM, Rapoport TA: Retrotranslocation of a misfolded luminal ER protein by ubiquitin-ligase Hrd1p. Cell 2010, 143:579-591.

5. Turner GC, Varshavsky A: Detecting and measuring cotranslational protein degradation in vivo. Science 2000, 289:2117-2120. 
6. Schubert U, Antón LC, Gibbs J, Norbury CC, Yewdell JW, Bennink JR: Nature 2000, 404:770-774

7. Bengtson MH, Joazeiro CAP: Role of a ribosome-associated E3 ubiquitin ligase in protein quality control. Nature 2010, 467:470-473.

8. Tsai YC, Weissman AM: The Unfolded Protein Response, Degradation from Endoplasmic Reticulum and Cancer. Genes Cancer 2010, 1:764-778.

9. Douglas PM, Dillin A: Protein homeostasis and aging in neurodegeneration. J Cell Biol 2010, 190:719-729.

10. Bedford L, Lowe J, Dick LR, Mayer RJ, Brownell JE: Ubiquitin-like protein conjugation and the ubiquitin-proteasome system as drug targets. Nat Rev Drug Discov 2011, 10:29-46.

11. Gardner RG, Shearer AG, Hampton RY: In vivo action of the HRD ubiquitin ligase complex: mechanisms of endoplasmic reticulum quality control and sterol regulation. Mol Cell Biol 2001, 21:4276-4291.

12. Schuck S, Prinz WA, Thorn KS, Voss C, Walter P: Membrane expansion alleviates endoplasmic reticulum stress independently of the unfolded protein response. J Cell Biol 2009, 187:525-536.

13. Wilson JD, Thompson SL, Barlowe C: Yet1p-Yet3p interacts with Scs $2 p$ Opi1p to regulate ER localization of the Opi1p repressor. Mol Biol Cell 2011, 22:1430-1439.

14. Rubio C, Pincus D, Korennykh A, Schuck S, El-Samad H, Walter P: Homeostatic adaptation to endoplasmic reticulum stress depends on Ire1 kinase activity. J Cell Biol 2011, 193:171-184.

15. Ismail N, Ng DT: Have you HRD? Understanding ERAD is DOAble! Cell 2006, 126:237-239

16. Haynes CM, Caldwell S, Cooper AA: An HRD/DER-independent ER quality control mechanism involves Rsp5p-dependent ubiquitination and ERGolgi transport. J Cell Biol 2002, 158:91-101.

17. Spear ED, Ng DT: Stress tolerance of misfolded carboxypeptidase $Y$ requires maintenance of protein trafficking and degradative pathways. Mol Biol Cell 2003, 14:2756-2767.

18. Philip B, Levin DE: Wsc1 and Mid2 are cell surface sensors for cell wall integrity signaling that act through Rom2, a guanine nucleotide exchange factor for Rho1. Mol Cell Biol 2001, 21:271-280

19. Fasolo J, Sboner A, Sun MG, Yu H, Chen R, Sharon D, Kim PM, Gerstein M, Snyder M: Diverse protein kinase interactions identified by protein microarrays reveal novel connections between cellular processes. Genes Dev 2011, 25:767-778.

20. Travers KJ, Patil CK, Wodicka L, Lockhart DJ, Weissman JS, Walter P: Functional and genomic analyses reveal an essential coordination between the unfolded protein response and ER-associated degradation. Cell 2000, 101:249-258.

21. Pineau $L$, Ferreira T: Lipid-induced ER stress in yeast and $\beta$ cells: parallel trails to a common fate. FEMS Yeast Res 2010, 10:1035-1045.

22. Hesselberth JR, Miller JP, Golob A, Stajich JE, Michaud GA, Fields S: Comparative analysis of Saccharomyces cerevisiae WW domains and their interacting proteins. Genome Biol 2006, 7:R30.

23. Hart GT, Lee I, Marcotte ER: A high-accuracy consensus map of yeast protein complexes reveals modular nature of gene essentiality. BMC Bioinformatics 2007, 8:236.

24. Saeki Y, Kudo T, Kawamura H, Tanaka K: Multiple proteasome-interacting proteins assist the assembly of the yeast $19 \mathrm{~S}$ regulatory particle. Cell 2009, 137:900-913.

25. Veitch DP, Gilham D, Cornell RB: The role of histidine residues in the HXGH site of CTP:phosphocholine cytidylyltransferase in CTP binding and catalysis. Eur J Biochem 1998, 255:227-234.

26. Howe AG, Zaremberg V, MCMaster CR: Cessation of growth to prevent cell death due to inhibition of phosphatidylcholine synthesis is impaired at 37 degrees C in Saccharomyces cerevisiae. J Biol Chem 2002, 277:44100-44107.

27. Biederer T, Volkwein C, Sommer T: Role of Cue $1 \mathrm{p}$ in ubiquitination and degradation at the ER surface. Science 1997, 278:1806-1809.

28. Steel GJ, Fullerton DM, Tyson JR, Stirling CJ: Coordinated activation of Hsp70 chaperones. Science 2004, 303:98-101.

29. Pitre S, Dehne F, Chan A, Cheetham J, Duong A, Emili A, Gebbia M, Greenblatt J, Jessulat M, Krogan N, Luo X, Golshani A: PIPE: a proteinprotein interaction prediction engine based on the re-occurring short polypeptide sequences between known interacting protein pairs. BMC Bioinformatics 2006, 7:365.
30. Michelsen K, Schmid V, Metz J, Heusser K, Liebel U, Schwede T, Spang A, Schwappach B: Novel cargo-binding site in the beta and delta subunits of coatomer. J Cell Biol 2007, 179:209-217.

31. Fleming JA, Lightcap ES, Sadis S, Thoroddsen V, Bulawa CE, Blackman RK: Complementary whole-genome technologies reveal the cellular response to proteasome inhibition by PS-341. Proc Natl Acad Sci USA 2002, 99:1461-1466.

32. Weinberg F, Hamanaka R, Wheaton WW, Weinberg S, Joseph J, Lopez M, Kalyanaraman B, Mutlu GM, Budinger GR, Chandel NS: Mitochondrial metabolism and ROS generation are essential for Kras-mediated tumorigenicity. Proc Natl Acad Sci USA 2010, 107:8788-8793.

33. Hamanaka RB, Chandel NS: Mitochondrial reactive oxygen species regulate cellular signaling and dictate biological outcomes. Trends Biochem Sci 2010, 35:505-513.

34. Meyer $\mathrm{HH}$, Kondo $\mathrm{H}$, Warren $\mathrm{G}$ : The $\mathrm{p} 47$ co-factor regulates the ATPase activity of the membrane fusion protein, p97. FEBS Lett 1998, 437:255-257

35. Ye Y, Meyer $\mathrm{HH}$, Rapoport TA: Function of p97-Ufd1-Npl4 complex in retrotranslocation from the ER to the cytosol: dual recognition of nonubiquitinated polypeptide segments and polyubiquitin chains. J Cell Biol 2003, 162:71-84

36. Wang S, Ng DT: Evasion of endoplasmic reticulum surveillance makes Wsc1p an obligate substrate of Golgi quality control. Mol Biol Cell 2010, 21:1153-1165.

37. Behrends C, Sowa ME, Gygi SP, Harper JW: Network organization of the human autophagy system. Nature 2010, 466:68-76.

38. Dowd SR, Bier ME, Patton-Vogt JL: Turnover of phosphatidylcholine in Saccharomyces cerevisiae. The role of the CDP-choline pathway. J Biol Chem 2001, 276:3756-3763.

39. Prinz S, Avila-Campillo I, Aldridge C, Srinivasan A, Dimitrov K, Siegel AF, Galitski T: Control of yeast filamentous-form growth by modules in an integrated molecular network. Genome Res 2004, 14:380-390.

40. Rida PC, Nishikawa A, Won GY, Dean N: Yeast-to-hyphal transition triggers formin-dependent Golgi localization to the growing tip in Candida albicans. Mol Biol Cell 2006, 17:4364-4378.

41. Wimalasena T, Enjalbert B, Guillemette T, Plumridge A, Budge S, Yin Z, Brown AJ, Archer DB: Impact of the unfolded protein response upon genome-wide expression patterns, and the role of $\mathrm{Hac} 1$ in the polarized growth, of Candida albicans. Fungal Genet Biol 2008, 45:1235-1247.

42. Colomina N, Ferrezuelo F, Vergés E, Aldea M, Garí E: Whi3 regulates morphogenesis in budding yeast by enhancing $\mathrm{Cdk}$ functions in apical growth. Cell Cycle 2009, 8:1912-1920.

43. Ausubel FM, Brent R, Moore DD, Seidman JA, Smith JA, Struhl K: Current Protocols in Molecular Biology John Wiley \& Sons, Inc., New York, NY; 1998, 13.0.3-13.13.7.

44. Sohal PS, Cornell RB: Sphingosine inhibits the activity of rat liver CTP: phosphocholine cytidylyltransferase. J Biol Chem 1990, 265:11746-11750.

doi:10.1186/1471-2180-11-268

Cite this article as: Costa et al:: The promoter of filamentation (POF1) protein from Saccharomyces cerevisiae is an ATPase involved in the protein quality control process. BMC Microbiology 2011 11:268.

\section{Submit your next manuscript to BioMed Central and take full advantage of:}

- Convenient online submission

- Thorough peer review

- No space constraints or color figure charges

- Immediate publication on acceptance

- Inclusion in PubMed, CAS, Scopus and Google Scholar

- Research which is freely available for redistribution

Submit your manuscript at www.biomedcentral com/submit
C Biomed Central 